\title{
CAN STREUMER SIMPLY AVOID SUPERVENIENCE?
}

\author{
Luke Elson
}

0 ART STREUMER has recently defended an error theory for all normative claims. ${ }^{1}$ Streumer's argument is by elimination: he offers original arguments against all competing metaethical views. A major such competitor is non-reductive realism about the normative. This view holds that there are irreducibly normative properties that are not identical to natural or descriptive properties.

To see Streumer's argument against non-reductive realism, first consider Frank Jackson's famous reduction argument against that view. Jackson's argument depends on the supervenience of the normative on the descriptive:

s: For all possible worlds $w$ and $w^{*}$, if the instantiation of descriptive properties in $w$ and $w^{*}$ is exactly the same, then the instantiation of normative properties in $w$ and $w^{*}$ is also exactly the same. ${ }^{2}$

Jackson's main idea is this: given a normative predicate such as "is wrong," the truth of supervenience allows us to construct a highly artificial descriptive predicate that is necessarily co-extensive with the normative predicate. ${ }^{3}$

Now, consider the following criterion of property identity:

$\mathrm{N}$ : Two predicates ascribe the same property iff they are necessarily coextensive. $^{4}$

If this criterion is correct, then the normative predicate and its artificial descriptive counterpart ascribe the same property. This implies that non-reductive realism is false, at least assuming that the "shared" property is a descriptive one.

There are obviously many places to object to this argument. For example,

1 Streumer, Unbelievable Errors.

2 Streumer, Unbelievable Errors, 25.

3 Jackson, "From Metaphysics to Ethics," 122-23.

4 Streumer, Unbelievable Errors, 30. 
one might object to the distinction between normative and descriptive predicates, or to the criterion of property identity $\mathrm{N}$.

One of its (apparently) less controversial aspects is the supervenience claim s. But $\mathrm{s}$ has recently been questioned. ${ }^{5}$ Streumer offers a new version of the reduction argument that putatively "does not appeal to any claim about supervenience at all."

If Streumer's version of the reduction argument indeed avoids appeal to supervenience, then this is significant even for non-error theorists. Most obviously, it would add to the stock of arguments against non-reductive realism, and reduce their dependence on s. Critics of non-reductive realism (including both error theorists and other brands of realist) should welcome a new argument against that view, especially one that relies on weaker assumptions.

In this article, however, I will argue that Streumer's argument indeed relies on supervenience. The dependence is more opaque than in Jackson's version of the argument, but without $\mathrm{s}$, the argument fails. ${ }^{7}$

\section{STREUMER'S SIMPLE MORAL THEORY ARGUMENT}

To get the argument going, we first assume that some simple moral theory is correct. ${ }^{8}$ By way of example, take hedonistic act utilitarianism:

Utilitarianism: Necessarily, an action is right if and only if it maximizes happiness. ${ }^{9}$

Since "maximizes happiness" is a descriptive predicate, Utilitarianism says that "is right" is co-extensive with a descriptive predicate ("maximizes happiness"), and that this co-extension holds across all possible worlds. In other words, Utilitarianism implies:

5 For discussion and references, see Väyrynen, "The Supervenience Challenge to Non-Naturalism."

6 Streumer, Unbelievable Errors, 26, 30-35. An earlier version appeared in Streumer, "Why There Really Are No Irreducibly Normative Properties," 315-18.

7 Dunaway also discusses reduction without supervenience ("Supervenience Arguments and Normative Non-Naturalism”). I will not consider his view here, because I am evaluating whether Streumer's argument is a distinctive supervenience-avoiding refutation of non-reductive realism.

8 The normative property in question throughout is that of moral rightness, but the argument is intended to extend to all normative properties.

9 Streumer, Unbelievable Errors, 30. 
Right-Description Necessity: The predicate "is right" is necessarily co-extensive with a descriptive predicate. ${ }^{10}$

Now, applying N, Right-Description Necessity in turn implies that rightness and a descriptive property (in this case, maximizing happiness) are the same property. So non-reductive realism is false.

We reached this conclusion by assuming that the correct moral theory is simple, and that it is Utilitarianism. But the conclusion would not be very interesting if it relied on these assumptions. So Streumer appeals to the following principle:

$\mathrm{w}$ : Whether normative properties are identical to descriptive properties cannot depend on which first-order normative view is correct. ${ }^{11}$

If $\mathrm{w}$ is true, then nothing hung on the truth of Utilitarianism, or more generally on the truth of a simple first-order moral view. So the assumptions can be dropped, but the conclusion - that non-reductive realism is false-stands.

The supervenience claim s did not explicitly feature in this argument. But, I will argue, the argument nevertheless depends on s: its conclusion applies only to moral theories that imply the truth of supervenience. In particular, the modal operator "necessarily" in Utilitarianism smuggles in the supervenience claim.

\section{REDUCTION-FRIENDLY THEORIES}

The heart of my criticism is this: Right-Description Necessity amounts to supervenience, and the argument succeeds only for that restricted set of first-order moral theories that entails Right-Description Necessity. Therefore, the argument covertly relies on $\mathrm{s}$.

Utilitarianism has the following structure: necessarily, an act $x$ is right iff $\phi(x)$, where $\phi$ is a descriptive predicate. In other words, Utilitarianism ascribes a necessary and sufficient condition $\phi$ for rightness, where $\phi$ is descriptive, and says that this biconditional holds necessarily. Call first-order moral theories with this structure "reduction friendly."

Clearly, any reduction-friendly moral theory implies Right-Description Necessity. But Right-Description Necessity entails supervenience. To see this, suppose that two worlds $w$ and $w^{*}$ are such that all descriptive properties are the same. $\phi$ is a descriptive property, so the same acts are $\phi$ in $w$ and $w^{*}$. Therefore,

10 As Streumer puts it: "If [Utilitarianism] is correct, the predicate 'is right' is necessarily coextensive with the descriptive predicate 'maximizes happiness'” (Unbelievable Errors, 31). I take this - and the other necessity claims in play—to involve a kind of metaphysical necessity: moral theories that violate it are not logically incoherent. 
and applying our reduction-friendly theory of the normative property in question, the same acts have that normative property in $w$ and $w^{*}$. But this is just a statement of $s$.

So Streumer's chosen example happens to be one that implies supervenience. But could his argument instead work with some other simple moral theoryone that does not imply s?

To see why not, consider some other putative moral theories. These examples show that a moral theory that is not reduction friendly either fails to entail Right-Description Necessity (and is silent on the question of supervenience), or entails the falsity of Right-Description Necessity (and the falsity of supervenience).

First:

Simpler Utilitarianism: For all actions $x$ in the actual world, $x$ is right if and only if $x$ maximizes happiness.

Simpler Utilitarianism is a universally quantified biconditional with no modal content. It says that an act in our world is right iff that act has a descriptive property (maximizing happiness). But Simpler Utilitarianism does not say anything about rightness in other possible worlds. For this reason, Simpler Utilitarianism implies neither Right-Description Necessity nor supervenience. It is compatible with Simpler Utilitarianism that in some other possible world, actions are right iff they have some other descriptive property (such as minimizing utility or being done on a Tuesday), or that there is no descriptive predicate that is co-extensive with rightness in that world. Because Simpler Utilitarianism is not reduction friendly, it does not imply Right-Description Necessity, and Streumer's argument does not go through. ${ }^{12}$

Second, a more extreme example:

Completeness: Every logically possible distribution of rightness over descriptive properties is realized in some possible world.

Completeness implies the falsity of Right-Description Necessity. Here is why. It is logically possible that the normative property of being a right action is co-extensive with the descriptive property of being an act done on a Tuesday; it is logically possible that the normative property of being a right action is co-extensive with the descriptive property of being an act done on a Wednesday.

Now, consider two possible worlds that are descriptively identical, and in which Bart Streumer buys a cup of coffee on some Wednesday. According to

12 But, as I will argue below, Simpler Utilitarianism is the kind of theory that makes w look plausible. 
Completeness, Streumer's act of buying a coffee is wrong in one world (because done on Wednesday, not Tuesday), and right in the other world (because done on Wednesday).

So if Completeness is the correct moral theory, then Streumer's argument fails, because the correct moral theory does not imply Right-Description Necessity. Completeness also implies that $\mathrm{S}$ is false, because the two possible worlds are descriptively identical, but differ normatively.

These examples show how Streumer's argument fails more generally. The structure of the argument is that if we assume a simple moral theory such as Utilitarianism, then we see that Right-Description Necessity is true, and therefore by appeal to $\mathrm{N}$ that non-reductive realism is false. Then $\mathrm{w}$ tells us that the choice of Utilitarianism played no logical role, and thus that we can drop the assumption of that particular moral theory, yet keep the conclusion that non-reductive realism is false.

But if I am right, then the work in the argument is done not by the simplicity of Utilitarianism, but by its reduction friendliness. And this reduction friendliness does play a logical role in the argument: if the true moral theory is not reduction friendly, then non-reductive realism is not refuted. So the assumption that the true moral theory is reduction friendly cannot be dropped-and reduction friendliness implies s.

An anonymous reviewer has suggested the following ingenious response to my criticism: What if there is some constraint on what counts as a theory-or more specifically, on what counts as a moral theory? We might think that theories in general, or moral theories in particular, must be able to ground counterfactuals, or respect universalizability, for example. If there are such constraints, might they rule Simpler Utilitarianism and Completeness ineligible as theories, let alone as moral theories, let alone as possibly correct moral theories?

Though I agree that this is the best line of response for Streumer, here is a general argument that it cannot work. The response faces a dilemma.

First, suppose that there is such a constraint-for the sake of argument, a constraint on what counts as a moral theory. If the constraint restricts moral theories to the reduction-friendly (and so supervenience-implying) ones only, then Streumer's argument is not independent of supervenience after all. The argument relies on a truth that all moral theories imply supervenience. It covertly assumes $\mathrm{s}$ by relying on constraints that entail $\mathrm{s}$.

On the other hand, if the constraint does not restrict moral theories to the reduction friendly-if some non-reduction-friendly moral theory meets the constraint-then my earlier criticism stands. Whatever the eligible but non-reduction-friendly moral theory in question, substitute it for Completeness in the 
counterexample above. Because the theory is not reduction friendly, it does not imply Right-Description Necessity, and Streumer's argument does not get underway.

So restricting which (moral) theories are in play does not seem to be a promising line of response.

But Streumer could say: if the correct moral theory is simple and reduction friendly, then it need not matter that there are other possible moral theories that are neither simple nor reduction friendly. We just need to assume that a simple and reduction-friendly theory is correct, show that Right-Description Necessity follows, and then use $\mathrm{w}$ to generalize the conclusion (that non-reductive realism is false) to the other moral theories, whether they are reduction friendly or not. To close off this line of response, I will criticize w.

\section{AN ERROR THEORY FOR W}

Streumer's argument relies on w, which is:

w: Whether normative properties are identical to descriptive properties cannot depend on which first-order normative view is correct. ${ }^{13}$

I will remain neutral on what kind of dependence is at stake in w. Implicitly, I have been arguing that $\mathrm{w}$ is false. Given some assumptions, including N, I showed that some first-order normative views (the reduction-friendly ones) imply that normative properties are identical to descriptive properties, but some other first-order normative views (the non-reduction-friendly ones) either imply that normative properties are not identical to descriptive properties or are silent about the matter.

In other words, I have argued against Streumer's claim that neither non-reductive realism nor its denial "contradicts any first-order normative view at all." His master argument fails because it applies only to a restricted range of first-order theories.

In this section, I will show more explicitly that $\mathrm{w}$ is false, and explain why it seems so plausible. Let us again focus on the moral. What is a first-order moral theory? Roughly, it will tell us

(i) which objects have which moral properties, and which descriptive properties these objects have. ${ }^{15}$

13 Streumer, Unbelievable Errors, 31.

14 Streumer, Unbelievable Errors, 33.

15 Compare Streumer, Unbelievable Errors, 31. 
For Streumer, answering (i) simply is—conceptually-what a moral theory does. He defends w by claiming that whether non-reductive realism is true instead

(ii) "seems to depend on the nature of [moral $]$ properties." 16

So the argument for $\mathrm{w}$ is that (i) and (ii) are distinct questions; indeed, $\mathrm{w}$ arguably simply states that they are distinct. Clearly, the plausibility of $\mathrm{w}$ depends on keeping (i) and (ii) distinct.

But if the correct criterion of property identity is $\mathrm{N}$, then the distinction between them collapses. This is because (i)-type facts about whether all objects with moral rightness also, across all worlds, have some descriptive property can imply-according to $\mathrm{N}-\mathrm{a}$ (ii)-type fact about the nature of moral rightness: whether moral rightness is identical to that descriptive property.

If the (i)-type facts in question are modally strong, and tell us about how moral and descriptive properties are distributed across all possible worlds, then they can satisfy the antecedent of $\mathrm{N}$. This is just what reduction-friendly first-order moral theories do, and why it is the reduction friendliness (and not the simplicity) of those theories that does the work in that part of Streumer's argument. w cannot be used to hold fixed (ii)-type facts about non-reductive realism while ranging across both reduction-friendly and non-reduction-friendly answers to (i). In slogan, w says that first-order theories and metaethical theories answer distinctive questions. But given $\mathrm{N}$ and modally strong first-order moral theories, the distinction breaks down.

There are two main ways that Streumer could rescue w. First, he could say that $\mathrm{N}$ is false: even if our first-order moral theory says that rightness is necessarily co-extensive with a descriptive predicate, this does not imply anything about property identity. But of course then the conclusion of his argument-the falsity of non-reductive realism-would not follow, because $\mathrm{N}$ is a crucial premise in that argument.

Second, he could restrict $\mathrm{w}$ in a way that is compatible with $\mathrm{N}$ :

Weak w: Whether some normative property is identical to a descriptive property cannot depend only on what things in this possible world have that normative property.

This claim is indeed plausible, and compatible with $\mathrm{N}$. It says that, for example, whether non-reductive realism is true cannot depend only on whether Simpler Utilitarianism is correct. Weak $\mathrm{w}$ is compatible with $\mathrm{N}$ because the latter says that to imply facts about property identity, a moral theory must say something

16 Streumer, Unbelievable Errors, 31. 
about the moral property across all possible worlds, not just this one or just a few of them.

But as we saw with that example, Simpler Utilitarianism is not modally strong enough to entail Right-Description Necessity. A first-order moral theory that only tells us about wrongness in this possible world is not sufficient for Streumer's argument to proceed.

But why does $\mathrm{w}$ seem plausible, even in the presence of $\mathrm{N}$ ? Here is my diagnosis. First, Weak $\mathrm{w}$ is very plausible, and because of that we have failed to notice how implausible $\mathrm{W}$ is, at least in the presence of $\mathrm{N}$ and of first-order moral theories that include claims about all possible worlds. Second, w itself is very plausible if we are not attached to $\mathrm{N}$ - both non-reductive realists and reductive realists can accept $\mathrm{w}$, but not at the same time as $\mathrm{N}^{17}$

\title{
4. CONCLUSION
}

I have argued that Streumer's attempt at reduction without s fails. The simple moral theory argument might not explicitly depend on supervenience, but it succeeds only for reduction-friendly moral theories - and those theories entail the truth of supervenience. ${ }^{18}$

\author{
University of Reading \\ luke.elson@reading.ac.uk
}

\section{REFERENCES}

Dunaway, Billy. "Supervenience Arguments and Normative Non-Naturalism." Philosophy and Phenomenological Research 91, no. 3 (November 2015): 627-55. Jackson, Frank. From Metaphysics to Ethics. Oxford: Oxford University Press, 1998.

Streumer, Bart. Unbelievable Errors. Oxford: Oxford University Press, 2017. "Why There Really Are No Irreducibly Normative Properties." In Thinking About Reasons: Themes from the Philosophy of Jonathan Dancy, edited by

17 At least, as we have seen, not without constraints on what counts as a moral theory that restricts $\mathrm{w}$ to either the reduction friendly or to the non-reduction friendly.

$18 \mathrm{I}$ am indebted to Bart Streumer, members of a seminar at the University of Groningen, and an anonymous reviewer for discussion and comments. I gratefully acknowledge funding from the European Union, H2O2O-MSCA-IF-2016 grant 748617, "Austere Reasons." 
David Bakhurst, Brad Hooker, and Margaret Little, 310-36. Oxford: Oxford University Press, 2013.

Väyrynen, Pekka. "The Supervenience Challenge to Non-Naturalism." In The Routledge Handbook of Metaethics, edited by Tristram McPherson and David Plunkett, 170-84. New York: Routledge, 2017. 